\title{
Formação inicial de professores de Ciências: perspectiva discursiva na educação CTS
}

\section{Initial education of Science teachers: discursive perspective in STS education}

\author{
Suzani Cassiani* \\ Irlan von Linsingen**
}

\begin{abstract}
RESUMO
Neste estudo apresentamos algumas reflexões sobre um trabalho realizado em salas de aula de oitavas séries de ciências, realizado por turmas da licenciatura em Ciências Biológicas, especificamente nas disciplinas de Metodologia e Instrumentação para o Ensino de Ciências. O objetivo principal é criar possibilidades dos licenciandos vivenciarem o cotidiano de uma escola pública, desenvolvendo uma intervenção didática numa perspectiva discursiva na educação CTS. Dessa forma, nossas referências têm se pautado na análise do discurso e no funcionamento da linguagem em aulas de ciências e tecnologia. São apresentados e discutidos alguns resultados dessa proposta de formação inicial de professores e a pertinência da abordagem temática para a construção de sentidos sociais-culturais e ambientais do conhecimento científico contextualizado.

Palavras-chave: Análise do Discurso; educação CTS; formação de professores.
\end{abstract}

\footnotetext{
ABSTRACT

In this study, we present some reflections on a work in classrooms of eigth grade, done by a class of Biological Sciences, specifically in the disciplines of Methodology and Instrumentation for the Science Teaching. The main

* Doutora em Educação. Instituição atual: Programa de Pós Graduação em Educação Científica e Tecnológica - Universidade Federal de Santa Catarina.

** Doutor em Educação. Instituição atual: Programa de Pós Graduação em Educação Científica e Tecnológica - Universidade Federal de Santa Catarina.
} 
goal is to create opportunities for future teachers to experience daily life in a public school, developing an intervention in a didactic discursive perspective in STS education. Thus, our references have been based on analysis of speech and functioning of language in science and technology classes. We presented and discussed some results over the initial education of science teachers and the relevance of thematic approach for the construction of social-cultural and environmental meanings of the contextualized scientific knowledge.

Keywords: Discourse Analysis; STS education; teacher education.

Neste estudo apresentamos algumas reflexões sobre um trabalho realizado em salas de aula da licenciatura em Ciências Biológicas, especificamente nas disciplinas de Metodologia e Instrumentação para o Ensino de Ciências, cujo objetivo principal é criar possibilidades dos licenciandos vivenciarem o cotidiano de uma escola pública, desenvolvendo uma intervenção didática na última série do ensino fundamental (oitava série), na disciplina de ciências.

Para o contexto da pesquisa, essas "intervenções", as quais vêm ocorrendo desde 2002, são tentativas de antecipar vivências que eram comumente realizadas apenas durante a Prática de Ensino ${ }^{1}$, que ocorriam na última fase da licenciatura ${ }^{2}$.

O Estágio Curricular na formação de professores sempre foi uma de nossas preocupações, pois considerávamos que o seu funcionamento nos cursos de licenciatura ficava muito aquém do desejado, considerando as inúmeras possibilidades que poderiam ser exploradas, mesmo com os limites da legislação anterior. Por aquela legislação, além do número de horas/aula a serem trabalhadas na disciplina de Prática de Ensino (180h) ser bastante reduzido, apresentava uma concepção de prática mais voltada à racionalidade técnica, ou seja, os cursos de licenciatura eram organizados no formato $3+1$, em que a teoria era oferecida nos três primeiros anos e depois a prática era trabalhada apenas como uma aplicação dos conhecimentos teóricos adquiridos. Não se via, na prática, uma perspectiva de aprendizagem. Como entendemos que o Estágio Curricular não é apenas aplicação de teoria, mas lócus de conhecimento, aquele formato não era adequado.

Segundo Pimenta (2000), essa desarticulação do Estágio Curricular estava relacionada à ausência de relações entre "o que ensinar", "como ensinar" e "a quem ensinar", o que acabava por provocar uma dicotomia entre teoria e prática.

1. O nome atual dessa disciplina é Estágio Supervisionado aqui também chamado de Estágio Curricular.

2. Um novo currículo está sendo implantado no curso de Ciências Biológicas da UFSC. 
Em relação a esse quadro, as atuais diretrizes curriculares sobre Formação de Professores (Resolução CNE/CP n. ${ }^{\circ}$ 01, de 18.02.2002), avançam em diversas direções, principalmente nos aspectos relacionados à antecipação do contato dos futuros professores com os seus possíveis ambientes de trabalho, nesse caso, ambientes escolares. Há também uma clara sinalização da necessária articulação do estudo de conceitos e modelos, suas fundamentações históricas, sociológicas e filosóficas, com a análise de situações reais vivenciadas ou situações-problema propostas (hipotéticas ou não). Em outros termos, reafirma-se a propalada articulação entre as dimensões teórica e prática de uma formação profissional (TERRAZZAN, 2003). Um exemplo dessa articulação pode ser identificado quando pensamos as 400 horas de Práticas como Componente Curricular (PCC), além das $400 \mathrm{~h}$ do Estágio Curricular, contemplados na Resolução $\mathrm{CNE} / \mathrm{CP} \mathrm{n}^{\circ}$. 02, de 18.02.2002, a qual propõe que:

\begin{abstract}
A prática como componente curricular é, pois, uma prática que produz algo no âmbito do ensino. [...] ela deve ser planejada quando da elaboração do projeto pedagógico e seu acontecer deve se dar desde o início da duração do processo formativo e se estender ao longo de todo o seu processo. [...] ela concorre conjuntamente para a formação da identidade do professor como educador (Parecer CNE/CP 28/2001, p. 9).
\end{abstract}

Antes mesmo que a legislação entrasse em vigor, as vivências que vamos abordar foram propostas ao percebermos que muitos licenciandos chegavam ao final da licenciatura sem conhecer o espaço escolar: a escola, seus estudantes e professores, sua rotina, seus projetos. Isso só ocorria efetivamente durante o Estágio Curricular.

Em pesquisas anteriores (CASSIANI-SOUZA et al., 2004), onde investigamos algumas das condições de produção de sentidos sobre os estágios curriculares, constatamos que parte dos licenciandos apresentava, em seu imaginário sobre a escola pública ${ }^{3}$, um medo desta e dos estudantes que nela estavam, principalmente por nunca terem estudado numa escola pública no ensino básico:

3. Esclarecemos que optamos pela realização dos estágios somente em escolas públicas por vários motivos: privilegiar a educação pública em busca de melhoria de qualidade; reverter à população ao menos um pouco o investimento feito pelos brasileiros à universidade pública; problematizar preconceitos dos licenciados, os quais em sua maioria são advindos de escolas privadas e constroem um imaginário relacionado a uma percepção bastante negativa sobre a escola pública (crianças agressivas e miseráveis, professores despreparados e preguiçosos, escola totalmente negligenciada); há mais vagas na educação pública, e, portanto muitos serão professores da escola pública. 
A fama desse colégio não é muito boa entre as pessoas que moram no bairro, e esse fato me preocupou de início, pois não sabia como seria recebido pelos alunos. Realmente o colégio tem alguns problemas isolados com certos alunos, mas nada que justifique essa fama e isso tudo nada mais é do que boatos "do fulano que me contou". Estagiário (1. Sem. de 2004) (CASSIANI-SOUZA et al., 2004, p. 6).

Os futuros professores de ciências, em sua maioria de classe média, após uma trajetória de mais de 15 anos de escolarização formal, vivenciando perspectivas tradicionais em escolas voltadas geralmente ao exame vestibular, veem-se diante de um trabalho docente centralmente voltado para a educação de crianças de diferentes sócioculturas e de menor poder aquisitivo, sem que tenham sido expostos a uma adequada problematização tanto dessa perspectiva tradicional de ensino quanto de sua própria condição sóciocultural, o que costuma provocar reações que expressam as dificuldades decorrentes dessas diferenças.

Como decorrência dessas constatações, orientamos nossos esforços no sentido de antecipar situações de docência, não só para amenizar um possível impacto no estágio sobre as experiências anteriores dos licenciandos na posição de estudantes, mas também para um maior amadurecimento sobre o que é a educação pública, sobre os sentidos da escola pública em nossa sociedade, sobre um ensino para a cidadania, sobre os sujeitos da escola, seus alunos, professores, funcionários, pais, enfim, as relações dessa escola numa sociedade capitalista.

Nessa mesma perspectiva, várias discussões surgiram sobre o sentido do termo "ensino crítico", que parece ter se tornado a razão para o atendimento de quaisquer propósitos. Cabe, por essa construção, perguntar: o que vem a ser um ensino crítico? Seguindo esse tema, este trabalho também percorre a mesma trilha para aprofundamentos sobre o que é necessário para promover um ensino crítico, e o que isso tem a ver com ciência e com tecnologia, estas percebidas também numa perspectiva crítica.

\section{Contextualizando}

Nesse trabalho os licenciandos são desafiados a participar ativamente da elaboração, da aplicação e avaliação de uma proposta de ensino diferenciada. Ou seja, a escolha de um tema que faça parte do cotidiano dos estudantes, o planejamento das atividades e a aplicação de propostas alternativas ao ensino tradicional, num processo mais amplo que envolve a comunidade, o reconheci- 
mento dos problemas locais, a ação negociada numa perspectiva CTS, a avaliação do trabalho, enfim, vivenciarem limites e possibilidades na regência de salas de aula, através de uma imersão de três dias numa escola pública de uma pequena cidade do interior do estado de Santa Catarina-Brasil.

As propostas de ensino são geradas/definidas principalmente em função de situações vividas pelas pessoas daquela comunidade. É nosso entendimento que os temas das propostas, relacionados a situações-problema locais devem fazer sentido também dentro do ensino de ciências numa perspectiva CTS. Nesse intuito, são negociados temas que envolvam conflitos de interesses políticos, econômicos, sociais, ambientais e científicos.

A proposta educacional envolve discussões sobre a forma como esses temas podem ser trabalhados (fugindo da educação bancária, no sentido freireano) e tem se revelado muito oportuna e relevante no ensino fundamental, pois percebemos que constitui também um caminho para o professor propiciar aos estudantes uma ruptura com o senso comum.

Conforme comentamos em artigo anterior (LINSINGEN et al., 2007), ao longo do semestre, planejamos a atividade e, posteriormente, aplicamos a proposta de ensino na escola, iniciando com as seguintes problematizações:

- Que ciência e tecnologia queremos ensinar?

- Quais temas são relevantes para aquela comunidade?

- Como trabalhar numa perspectiva em que os seres humanos também fazem parte do "ambiente"?

- Como fazer uma discussão de forma problematizadora? O que é um problema?

- É possivel trabalhar a oitava série sem a fragmentação existente nos tradicionais livros didáticos de ciências, onde é enfatizado apenas a química e a física, cujos conteúdos são resumos superficiais do que será estudado no ensino médio?

- Como movimentar as concepções alternativas dos educandos?

- Como propor atividades nas quais possamos experimentar alguns processos investigativos de produção da ciência?

- Quais atividades de leitura e escrita podem ser propostas, resgatando hábitos que estão distantes do ensino de ciências, como, por exemplo, escrituras alternativas como os diários dos educandos?

A partir dessas ideias que também são discutidas e trabalhadas com os licenciandos, e consideradas as condições necessárias, um desafio é proposto à turma da disciplina de Instrumentação e Metodologia para o Ensino de Ciências: elaborar e aplicar uma proposta coletiva de ensino com a colaboração de todos os licenciandos da turma. Também é discutido com eles a pertinência de se levar em conta as especificidades da escola, que possui um currículo com 
tudo o que isto representa: objetivos, conteúdos, metodologias, avaliações. Além disso, há as expectativas e desejos dos alunos da escola, de seus pais, de seus professores, que também contribuem para as condições de produção daquele currículo. Enfim, tendo percebido que há intenções e sentidos priorizados nesse local e como nos encontramos nele, é preciso lidar com essas demandas.

Para ajudar a apreciar o que estamos tratando, a série em que propositalmente trabalhamos tem como tradição escolar a abordagem de conteúdos da física e da química de forma bastante fragmentada. Em nossa intervenção precisamos levar em conta isso. Então, a escolha da série também é desafiadora, já que esses licenciandos - futuros professores de ciências - são formados num curso com grande ênfase nas áreas da biologia. Conforme já enfatizamos em trabalhos anteriores (FLÔR; CASSIANI-SOUZA, 2005), apesar dos Parâmetros Curriculares Nacionais criticarem a fragmentação dos conteúdos, enfatizando a importância da interdisciplinaridade, ela ainda persiste no currículo da disciplina de ciências e, na $8 .^{a}$ série, não é diferente. Ao contrário, há um agravamento se pensarmos que isso implica até mesmo na escolha das turmas pelos professores efetivos e mais experientes, como ainda observamos nas escolas, já que os mesmos evitam optar por turmas de $8 .^{\text {a }}$ série, com receio ou desagrado em trabalhar a química e a física conforme trazem os livros didáticos ou como se organiza o currículo escolar, mesmo que de forma acrítica.

Ressaltamos essa situação, pois os livros geralmente optam por uma abordagem da química e da física nas oitavas séries como um resumo superficial do que será visto no ensino médio, enquanto nas séries anteriores são trabalhados os das geociências na 5. ${ }^{\mathrm{a}}$ série e biologia nas $6 .^{\mathrm{a}} \mathrm{e} 7 .^{\mathrm{a}}$ série (seres vivos e corpo humano, respectivamente).

Nesse caso, em nossa intervenção, o problema é então "driblar" a fragmentação proposta no currículo existente, ainda mais que a formação específica em biologia dos nossos licenciandos dificulta um trabalho que envolva outros conteúdos curriculares.

Nesse caminho, os estudantes da licenciatura são convidados a diminuir a fragmentação a que estamos sujeitos, através de temas que proporcionem, dentro da disciplina ciências, uma aproximação entre a vivência dos estudantes daquela escola e de sua própria vivência como estudante de biologia e futuro professor de ciências.

Então, os temas são gerados/definidos principalmente em função das situações vividas pelas pessoas daquela comunidade e propícios ao currículo da disciplina Ciências, os quais são sugeridos pelos professores da escola. Esses temas precisam fazer sentido no âmbito das relações CTS, ou seja, que possam ser tratados em seus aspectos políticos, econômicos, sociais, científicos, e que possam ser problematizados naquele contexto. São temas ligados ao 
cotidiano dos educandos, da forma como o entendemos (HELLER, 1985), ou seja, envolvem um entendimento da vida cotidiana que na maioria das vezes os sujeitos não têm acesso quando se pensa numa reflexão mais crítica sobre as suas vivências.

A percepção da necessidade de explorar assuntos que muitas vezes estão fora do currículo tradicional, aqui tratados numa perspectiva de CTS e AD, está estreitamente relacionada com a crítica de Michael Apple (1982) à tradição seletiva dos conteúdos, nos quais os assuntos polêmicos e históricos são silenciados no currículo mostrando uma ciência canônica e neutra. Por exemplo, no tema Leite (um dos temas trabalhados) os estudantes não conseguiam associar Pasteur à pasteurização, observada na indústria de laticínios ao lado da escola, e nem o tipo de influência que aquela indústria exerce nas suas vidas e na vida daquela comunidade, ou seja, a rede de relações que se estabelece (causa/efeito) em face do tema abordado.

Essa é uma questão primordial e necessária, pois acreditamos que a escola deve propiciar aos educandos uma ruptura com o senso comum. A possibilidade de olhar de forma diferente para o mesmo. Aprofundar, desvelar, descobrir, fazer o educando perceber que ele tem limites sobre o seu conhecimento. Fazê-lo pensar nesses limites do saber e do não saber. Repensar o que ele achava que sabia.

Todas as propostas envolvem conflitos e interesses da comunidade, sempre pensando nos limites e possibilidades para uma mesma questão. Tudo é feito coletivamente, desde a escolha do tema, as formas de abordagens metodológicas, o levantamento de informações, possíveis materiais didáticos, culminando na produção de uma proposta de ensino. Dessa forma, há toda uma construção de conhecimentos sobre o local. Pelas características da comunidade e do contexto deste trabalho, os temas trabalhados até hoje são: leite, agrotóxicos, lixo, pinus, mel, esgoto.

Como já dissemos, pautamos nossas reflexões e análises em referenciais teóricos e metodológicos da Análise de Discurso de linha francesa e do campo de estudos CTS (ECTS), e é sobre isso que iremos falar agora, expondo de que forma nos situamos nessas construções, como olhamos para essas questões e quais são as condições de produção de sentidos das propostas de ensino implementadas. 


\section{Nossas referências}

Temos trabalhado numa perspectiva discursiva que tem como forte referência a Análise de Discurso francesa. Temos refletido sobre as suas possíveis contribuições na educação e em diferentes níveis do ensino. Esta pressupõe que os sentidos são construídos e, apesar de sua inscrição na história, o sujeito é ativo na interpretação que produz. Conforme nos esclarece Orlandi (1996, p. 22) "o espaço da interpretação, é o espaço do possível, da falha, do efeito metafórico, do equívoco, em suma: do trabalho da história e do significante, em outras palavras, do trabalho do sujeito".

Partimos do pressuposto que as construções de sentidos que fazemos sobre os mais diversos aspectos em nossas vidas devem levar em conta as nossas histórias de vida, os conhecimentos construídos até o momento e as inúmeras expectativas sobre os assuntos a serem abordados. As experiências perceptivas não são iguais para todos e, portanto, trabalhamos na perspectiva de que o "a priori” não está dado e é preciso perceber essa sutileza da não transparência da linguagem. Pessoas fazem interpretações sobre os mais diversos assuntos e a escola não é um local diferente.

Em relação à perspectiva $\mathrm{CTS}$, temos elaborado reflexões críticas sobre os discursos dominantes da ciência e da tecnologia e sua legitimação na construção e aplicação de saberes, bem como suas prováveis consequências sobre a educação e suas relações com as tomadas de decisão sobre questões de C\&T na esfera pública.

Buscando ampliar a compreensão sobre essas questões numa perspectiva de ensino de/sobre ciência e tecnologia, usamos aqui como exemplo o seguinte texto:

Assistindo a gravação de uma enquête feita na rua, num povoado da região Norte por uma TV comunitária, vi alguém dizendo que o mosquito que transmite a AIDS é o "Aids do Egito". Façamos um percurso lógico do que parece ilógico: Na região Norte, as pessoas aprendem que grande parte das doenças se pega por picada de mosquito: $\rightarrow$ governo dissemina maciça campanha contra a dengue, e as pessoas aprendem que o vilão da doença é um mosquito que se chama "Aedes Egiptus (!!) $\rightarrow$ a formação mítica e religiosa da população associa o Egito com as sete pragas $\rightarrow \mathrm{O}$ mosquito é considerado uma praga, porque as pessoas nunca se livram das doenças que ele transmite $\rightarrow$ (malária, por exemplo) $\rightarrow$ paralelamente à campanha da dengue, é veiculada outra, contra a AIDS, nome que não faz nenhum sentido para a população, mas é muito parecido com AEDES, 
que também não faz nenhum sentido (Adaptado do texto "O AIDS DO EGITO E A COMUNICAÇÃO EM SAÚDE” de Inesita Araújo, Jornal Nós da Red, ano 1, n.3, 2000).

O que podemos interpretar sobre isso? Por que isso acontece e quais são as implicações na vida das pessoas, quando há interpretações deste tipo?

É necessário pensar nisso como um fenômeno da língua. Podemos dizer que os sujeitos interagem com as diferentes informações em que estão imersos e "produzem seus próprios textos", não necessariamente decodificando ou apreendendo o sentido que os autores quiseram efetivamente dar àquele texto (o sentido de texto aqui não é aquele apenas escrito e sim algo que podemos interpretar, podendo ser uma letra, um fato, um gesto, entre outros). Em relação ao exemplo usado, há que se pensar nas implicações sobre a transmissão da AIDS, e em como a escola é importante se conseguir trabalhar conhecimentos adequadamente a partir desse tipo de informação.

Daí a importância do tratamento do conhecimento científico e tecnológico numa perspectiva discursiva para as finalidades educacionais. Os estudos sociais da ciência e tecnologia, ou estudos de Ciência, Tecnologia e Sociedade (ECTS), particularmente estudos de caso podem ajudar na definição de temas e nas aproximações focais.

\section{Educação CTS numa perspectiva discursiva}

Educar, numa perspectiva CTS é, fundamentalmente, possibilitar uma formação para maior inserção social das pessoas no sentido de se tornarem aptas a participar dos processos de tomadas de decisões conscientes e negociadas em assuntos que envolvam ciência e tecnologia. Em outras palavras, é favorecer um ensino de/sobre ciência e tecnologia que vise à formação de indivíduos com a perspectiva de se tornarem cônscios de seus papéis como participantes ativos da transformação da sociedade em que vivem (LINSINGEN, 2007, p. 13).

Essa percepção educacional CTS possui implicações que vão muito além do desejo de construção de uma possibilidade de inserção social para um consumo consciente, e converge significativamente para aspectos proposicionais de democracia radical como proposto por Ernesto Laclau e Chantall Mouffe e de democracia participativa como percebida por Boaventura de Sousa Santos. O 
assunto é tratado por Marques (2008)4. Para a autora, as concepções hegemônicas de democracia tratam da participação democrática "como forma de legitimação de uma integração consentida", à qual se contrapõem "teorias democráticas que se colocam no campo das teorias não hegemônicas, nas quais a participação é um elemento de emancipação e, portanto, de mudança social".

A perspectiva educacional CTS parece ter se tornado um conceito polissêmico, de modo que cabe considerar que a abordagem aqui realizada pode ser compreendida como inserida no âmbito do que se tem denominado de perspectiva CTS crítica (DAGNINO, 2008), que entendemos aproximar-se da, e complementar a, perspectiva educacional crítica no sentido freireano (NASCIMENTO; LINSINGEN, 2006) convergindo, dessa maneira, para aquelas percepções não hegemônicas de democracia.

Não é uma abordagem que se possa fazer com facilidade no ensino de ciências, principalmente se pensarmos na multiplicidade e complexidade que envolve a educação escolar, do ato de ensinar e de todos os demais aspectos que não têm sido contemplados pelo enfoque CTS. Afinal, o que estamos fazendo é buscar aproximar o ensino de ciências dessa percepção de complexidade contextual que se abriu com a assunção da não neutralidade e não essencialidade da ciência, a partir dos ECTS.

Assim é que pensamos CTS numa perspectiva discursiva. As novas percepções das relações CTS, a partir das quais os sentidos hegemônicos conferidos ao ensino de ciências se transfiguram pela desnaturalização, favorecida por problematização e dialogicidade, abre as portas para a construção de novos sentidos sobre a ciência e a tecnologia e, implicadamente, para novas percepções de sociedade e dos papéis dos atores sociais.

São apresentados e discutidos, na sequência, alguns resultados dessa proposta de formação de professores e a pertinência da abordagem temática para a construção de sentidos sociais-culturais e ambientais do conhecimento científico contextualizado.

4. O artigo completo da autora pode ser encontrado em $<$ http://www.scielo.br/pdf/es/ v29n102/a0429102.pdf>. 


\section{Um novembro chuvoso ${ }^{5}$}

Para aprofundar o olhar, focamos um episódio ocorrido em 2008. Éramos sete contando com a professora da turma ${ }^{6}$. Os seis ${ }^{7}$ estudantes que participaram deixaram para trás demandas e obrigações, para naquele momento se dedicarem a uma viagem de campo exclusivamente da licenciatura, coisa rara num curso onde o bacharelado é tradicionalmente privilegiado.

Chovia naquele novembro de 2008 como nunca. Nas narrativas produzidas pelos nossos seis futuros professores há várias passagens contando as improvisações que realizamos em função da chuva contínua que prenunciava catástrofes em Santa Catarina, que ocorreram um dia após o nosso retorno a Florianópolis, inclusive na pousada em que estivemos, a qual teve uma parte soterrada e a estrada bloqueada por uma barreira que isolou a pequena cidade de São Bonifácio.

As dezenas de curvas que o ônibus fazia embalavam a conversa sobre nossa empreitada. Nas mochilas, o material das aulas preparadas nos meses antecedentes e nas cabeças as expectativas, a ansiedade, as angústias, a insegurança, entre outros sentimentos relatados nas narrativas. Para alguns deles era a "primeira experiência como professora de uma aluna do curso de ciências biológicas que há muito tempo aguardava (com muita ansiedade) por esta oportunidade e sua trajetória no curso com relação à licenciatura" (DANI). Ou "essa atividade foi meu primeiro contato prático com a licenciatura, diferente de outros colegas da turma que já tiveram essa experiência, e talvez por isso eu tenha me sentido bastante insegura no primeiro dia das atividades com as 8. ${ }^{a}$ séries" (BIANCA).

Chegamos à tardezinha e fomos direto para a pousada, que estava cheia de hortênsias floridas. Em meio a cortes de legumes sob as ordens de nossos chefs que cozinhavam um delicioso jantar vegetariano, conversávamos sobre o trabalho, discutindo os últimos detalhes do trabalho que se iniciaria logo às oito da manhã. Sabíamos que as duas turmas das oitavas séries seriam nossas naqueles dias e conforme Bárbara apontou que

5. Para trazer algumas condições de produção desse trabalho, esclarecemos que esse item foi produzido com as seis narrativas dos estudantes referentes ao trabalho realizado em novembro de 2008 .

6. Primeira autora desse trabalho.

7. Agradecemos aos licenciandos Bárbara Samartini Queiroz Alves, Bianca Luise Teixeira, Clara de Souza Corat, Danielle Ferraz Mello, Thiago Marques Ribeiro e Wilson Rodrigues S. Gonzáles que colaboraram imensamente com o desenvolvimento da proposta com muita responsabilidade, espírito de equipe, senso crítico e muito bom humor. 
graças a metodologia colocada pela professora, metodologia esta a qual sou inteiramente de acordo, cada pessoa havia ficado responsável por cada parte/atividade da aula e com isto a reunião pode proceder tranquilamente, pois a organização previamente decidida prevaleceu durante o repasse (do planejamento das aulas).

É importante esclarecer que em setembro já havíamos conhecido a cidade e a escola, onde tivemos uma conversa longa com o diretor da escola e um dos professores, os quais nos informaram como a questão dos dejetos animais começou a incomodar, quando os produtores se associaram a grandes empresas na criação de frango e porco em larga escala sem a preocupação com o tratamento dos efluentes. Depois desta saída, voltamos para a sala de aula com enfoque definido sobre a questão do esgoto doméstico e principalmente a questão dos dejetos de animais.

A partir dessa definição, o grupo dividiu tarefas relacionadas à temática $\mathrm{e}$ ao levantamento de informações sobre ela, além de informações locais sobre o esgoto e/ou qualidade da água. Além da busca de materiais para embasar nossa compreensão, também havia uma busca sobre materiais que pudessem ser trabalhados com os estudantes das oitavas séries, pensando no nível de aprofundamento dos conteúdos, trabalhos produzidos sobre o tema, como as concepções alternativas dos estudantes, além de formas diferenciadas de ensino, formas de problematização do tema, textos alternativos ao livro didático, experimentos, saídas de campo. Foram trazidos artigos sobre biodigestor, esgoto, produção de gases no sistema digestivo, vídeos, imagens. A partir da discussão dos materiais trazidos foram levantadas as seguintes questões: O que vamos ensinar? Como vamos trabalhar os conteúdos? Quais são nossos objetivos?

É bom lembrar que algo muito enfatizado durante os meses anteriores, quando do planejamento das atividades, foi o de que nada adiantaria um trabalho com diferentes conteúdos, em nosso caso o tema era "Esgoto" e toda sua problemática, se a forma trabalhada não fosse diferenciada. Além disso, discutimos o que era trabalhar sobre a perspectiva CTS como já foi dito anteriormente. Com objetivos elaborados coletivamente, chegamos ao seguinte:

- Analisar as condições sócioambientais focalizando o impacto dos efluentes;

- Problematizar o tema, as questões da cidade e apontar soluções/ alternativas;

- Incentivar o senso crítico;

- Tentar mostrar ao estudante que o conhecimento adquirido na escola é importante para entender o seu dia-a-dia. 
Nesse caminho, trazemos agora as impressões sobre alguns focos apontados nesse trabalho numa perspectiva discursiva, apresentados nas narrativas dos estudantes que contribuíram para sua formação através dessa vivência.

\section{Aprofundando o olhar}

Como já dissemos, partimos da premissa de que a linguagem não é transparente. Há outros sentidos possíveis e quando falamos aos estudantes não é diferente. Não há garantia de que o sentido privilegiado numa sala de aula pelo professor será efetivamente incorporado pelos estudantes. Também enfatizamos, em vários momentos na disciplina, o mecanismo de antecipação. Com isso trabalhamos a ideia de que quando falo, falo para os outros. Esse falar está repleto de intenções sobre o sujeito que está nos ouvindo, para que os sentidos sejam construídos baseados em nossos objetivos. Já que não temos controle sobre os sentidos, ao menos devemos ter certa preocupação em nos colocar no lugar do outro. Outro conceito importante foi a importância da não separação entre forma e conteúdo na educação CTS. Nesse sentido, é preciso romper o mito de que basta repensar o conteúdo e um trabalho inovador estará garantido. Pêcheux (1990) afirma que a forma como se diz também produz sentidos. Assim não se pode pensar em tal separação - forma e conteúdo - quando pensamos na construção de sentidos.

Ao trabalharmos essas questões na licenciatura, em síntese a importância do funcionamento da linguagem em salas de aula, o foco passa a ser o estudante. Na sequência focalizamos alguns aspectos de trechos das narrativas dos licenciandos. Por exemplo, nessa fala percebemos como eles passam a atentar para a linguagem e como ela precisa ser repensada quando se trabalha na escola básica:

Tivemos que tomar cuidado também com os termos utilizados, que acho que foi um problema maior para a Bianca que era um tema que envolve mais termos técnicos; nesse aspecto eu senti mais dificuldade enquanto estava dando aula nas minhas experiências anteriores, é muito difícil encontrar termos adequados, pois estamos acostumados com os termos técnicos (CLARA).

Explicar alguns temas pela complexidade aprendida nas aulas da universidade demonstrou um tanto quanto confuso na transposição para os alunos (WILSON). 
[...] eu aprendia muito observando ela atuar [a professora]. Um exemplo dessa situação foi quando ela interveio para perguntar aos alunos se eles entendiam o significado de um termo que tínhamos mencionado. E ao obter uma resposta negativa dos alunos, ela simplesmente não pegou e explicou o termo, pelo contrário, fazia mais perguntas até o ponto dos alunos conseguirem responder por si próprios o significado daquele termo. Isso me marcou muito e depois disso passei a me preocupar bastante sobre qual termo usar e procurar saber se eles entendiam os que eu eventualmente utilizava (DANI).

Nesse sentido, um outro aspecto observado foi a importância que os licenciandos deram ao tentar fazer com que os estudantes pensassem sobre o assunto e terem liberdade de perguntar:

Considerei essa uma experiência muito importante para mim, pude notar várias coisas que acho que me ajudarão muito no momento em que eu realmente for professora, coisas básicas para que a aula flua bem e para que o aluno fique interessado e se sinta parte do processo de aprendizagem, e não só alguém que tem que estar ali apenas recebendo informações..., além de dar-lhes a liberdade de fazer perguntas (CLARA).

[...] senti os alunos com mais liberdade para falar quando comparado à primeira parte da aula (WILSON).

Outro aspecto bastante enfatizado pelos licenciandos foi a importância da descontração, quando trabalhamos em sala de aula:

Pude notar que, em uma turma com muitos alunos, os professores têm que ser mais dinâmicos para prenderem a atenção de todos, ou da maioria, dos alunos. [...] E foram esses tipos de atividades que aconteceram nos dois dias de prática e que me mostraram ser essenciais para um bom aproveitamento dos alunos. A atividade de problematização do pum ${ }^{8}$ é um bom exemplo, pois despertou o interesse e curiosidade dos alunos, assim como demonstrou a possível inter-relação entre diversos conteúdos (BIANCA).

8. Uma das problematizações propostas foi "Por que soltamos pum?". Partimos dessa questão problematizadora, na qual os estudantes responderam baseados em suas próprias concepções, discutiram em pequeno e grande grupo e finalmente leram um texto com o mesmo título da Revista Ciência Hoje das Crianças. Disponível em: <http://cienciahoje.uol.com.br/oldsite/chc/ chc119a1.htm>. 
Neste momento percebi que deveria ser feito imediatamente algum tipo de brincadeira, algum tipo de descontração para quebrar o gelo. Porém, tive inicialmente uma dificuldade de transformar isto em prática por dois motivos, mais uma vez nervosismo aliado ao medo de ser reprovada por meus colegas (e professora) e sono. Admito aqui que estava sentindo muito sono neste momento da aula, até porque a sala estava escura ( 3 pares de lâmpadas florescentes não estavam funcionando), estava chovendo, era cedo, a turma estava inerte e o grupo estava nervoso (BÁRBARA).

Também, outro aspecto que foi observado e trabalhado nas aulas da licenciatura em várias disciplinas, é a forma como olhamos para as diferentes resistências dos estudantes. Um exemplo dessas discussões encontramos na fala de Danielle:

Neste semestre, estou realizando outra disciplina de licenciatura, Estrutura e Funcionamento do Ensino [...] que me permitiu que enxergasse os problemas escolares de um ponto de vista mais amplo. Esta disciplina abriu meus olhos para o fato de que o problema na verdade não está apenas nas escolas, sua estrutura, seus materiais disponíveis, ou modelo de aula do professor, e sim no modelo atual de sistema que rege a nossa sociedade, o capitalismo, o qual vem inevitavelmente acompanhado da exploração do trabalho, aumento das desigualdades sociais, exaltação do lucro, e conseqüentemente do consumismo, etc. [...] e foi dentro desse contexto, tendo consciência dessas questões, que a minha vontade de poder participar da vida escolar crescia cada vez mais. Queria ter a oportunidade de tentar interferir nesse ciclo que promove a manutenção do sistema capitalista, através da formação de pessoas com uma visão mais crítica a respeito do mundo que as rodeia. No entanto, as coisas não eram tão simples como eu imaginava. Eu tinha em mente que bastava você ser uma pessoa apaixonada pelo ato de ensinar, uma pessoa de bom senso com uma visão crítica de mundo e com consciência dos problemas que acometem as instituições de ensino, que você já seria um ótimo educador. Mas através desta prática pude perceber que essas características são realmente muito importantes, mas tem muito mais por trás de uma aula bem sucedida (DANI).

Nesse caminho, foi muito interessante notar como nossos licenciandos se posicionaram de uma forma diferenciada ao se depararem com algumas resistências dos estudantes: 
Por mais que várias destas crianças quisessem sustentar uma postura de descaso ou falta de interesse, eu sentia que tal comportamento não passava de imaturidade e que a curiosidade na verdade estava ali. Porém meio envergonhada de se fazer presente (THIAGO).

A vontade que dava era de jogar tudo para o alto, desencanar daqueles que não querem nada com nada e deu raiva de alguns quando eu olhava para eles e via que eles não se importavam com a sua presença ali. Eu queria então dizer: "seus inconseqüentes, fiquem aí sem fazer nada então, quem vai se dar mal são vocês!" E depois me voltar para aqueles alunos das primeiras carteiras e que se demonstravam interessados e dar aula só para eles, dialogar só com eles, cuidar só deles. Só que não dá, né? Sei que seria um absurdo desistir daqueles que simplesmente não se adaptam ao sistema e pior, um comodismo ou mediocridade despender energia só para aqueles que se demonstram estar de acordo você. Então persisti, continuei insistindo para que se esforçassem e continuei me esforçando para dar atenção para todos. O sinal bate, os alunos saem para o intervalo e eu me sentia cansada (BÁRBARA).

Mais um aspecto amplamente trabalhado e que muito aparece nas narrativas são as relações com o cotidiano. Essa palavra é bastante polissêmica e, embora muitos autores enfatizem que na educação CTS é necessário partir do "contexto ou cotidiano", isso muitas vezes aparece como um chavão ou aparentemente algo de fácil entendimento9. Ao trabalharmos com essas questões em nossas aulas, percebemos que um tema muito próximo ao estudante pode não despertar interesse, pois o aluno pode interpretar que sabe tudo sobre aquele determinado assunto.

Como já abordamos em outros trabalhos (CASSIANI-SOUZA, 2000), os sujeitos não sabem que não sabem. Isso pode trazer para a sala de aula baixas expectativas sobre a aprendizagem de determinado tema. Todas essas questões devem ser debatidas e problematizadas, pois consideramos fundamental a explicitação do conceito de cotidiano. Percebemos isso em vários momentos das falas dos licenciandos:

É preciso promover atividades que relacionem assuntos pelos quais os alunos se interessam, ou que sejam pertinentes à realidade deles. É importante que o professor não fique restrito a uma linha de pensamento, ou apenas a um conteúdo, e sim que inter-relacione conteúdos e pensamentos, inclusive dos próprios alunos (BIANCA).

9. O conceito de cotidianidade em Agnes Heller, aqui considerado, é discutido num artigo de Maria Helena S. Patto (1993). 
Achei muito interessante o fato de ficarmos questionando os alunos e extraindo os conhecimentos deles, pois eles começaram a ter que pensar sobre o que estavam falando e não somente repetir o que tinham lido ou escutado, tiveram que relacionar os conteúdos que havia sido passado pra eles anteriormente e também o cotidiano deles (CLARA).

Em outro foco, destacamos a importância que alguns licenciandos perceberam sobre a natureza da ciência e a necessidade de tentar ensinar que a ciência é uma construção humana, não é intocável ou algo neutro que está acima do bem e do mal. Apesar de muitas das narrativas não abordarem essa questão, percebemos que durante a atividade muitas vezes isso foi enfatizado. Para exemplificar, colocamos uma fala de Clara:

Percebi que assim fizemos os alunos pensar além do conteúdo que estava sendo passado ali, relacionando com as manchetes e notícias que eles ouviam, questionando certos pontos, e alguns deles inclusive tomaram "lados", e achei importante deixar bem claro que por mais que a discussão exista, aquele tipo de pesquisa é muito importante (CLARA).

A licencianda observou em sua prática a importância dessa discussão tão pouco trabalhada no ensino fundamental:

Algo interessante a ser ressaltado é que durante as discussões e nas apresentações pudemos mostrar aos alunos, mesmo que naquele momento não fosse de forma consciente, que a ciência possui muitas discussões e dúvidas dentro dela, não sendo algo pronto e intocável (CLARA).

Outro aspecto bastante importante trabalhado nesses anos todos na Escola São Tarcísio foi a importância do trabalho coletivo: as vantagens e desvanta-

\section{gens do trabalho em grupo.}

Por ser um trabalho de caráter democratizante, que nos evoca a criatividade e argumentação, contrapondo-se muitas vezes a nossa formação escolar, observamos que esse processo dialogado entre professora e licenciandos é uma aprendizagem que nos faz lidar com os conflitos, desenvolver a observação, perceber os vários grupos dentro de apenas um, aprender vendo o outro cole- 
ga, dividir as alegrias e responsabilidades. Abaixo apontamos algumas falas relacionadas a esse aspecto:

[...] Em minha opinião, o fato de haver muita gente intervindo, pode deixar os alunos um pouco confusos [...]. Houve também uma situação na qual eu estava questionando a atitude de uma aluna e outro professor [licenciando] fez um comentário que tirou toda a minha credibilidade naquele momento (DANI).

Creio que meu grupo realmente ficou com a turma mais complicada. E o fato de haver três pessoas responsáveis por turma muitas vezes criou situações de divergências no que diz respeito à postura em sala de aula e detalhes do conteúdo a ser abordado [...]. Nesse momento foi que senti como é difícil trabalhar em grupo. Acho que muitas vezes foram dadas como fato as opiniões dos professores (THIAGO).

Já na fala abaixo, a licencianda aponta para a importância do trabalho em grupo, quando os licenciandos expõem suas dúvidas aos estudantes, relativizando os saberes:

Considerei importante a discussão entre nós durante as explicações também, pois isso mostra um outro lado do professor para os alunos, que é muito raro de ser mostrado, o de que os professores divergem em suas opiniões e não tem todo o conhecimento nas mãos (CLARA).

Por outro lado, Thiago critica que:

Em outros momentos aprofundou-se muito o conteúdo, o que não estava proposto antecipadamente. Senti que muitas vezes estabelecemos uma relação de detentores do conhecimento (THIAGO).

Nessa outra fala, a licencianda vai além ao apontar para o receio que possui sobre uma possível avaliação subjetiva que os colegas fariam sobre a sua atuação: 
[...] ainda me sentia inibida, muito mais pelo pessoal da equipe [licenciandos], do que pelos alunos, tive medo de falar alguma bobagem ou interferir na parte de alguém em particular [...] ou por fazer algo que o grupo não estivesse de acordo (BÁRBARA).

Todas essas implicações que nos traz esse trabalho coletivo são possíveis, pois os licenciandos estão observando e refletindo sobre as suas próprias atuações e a de seus colegas:

\begin{abstract}
Ajudei meus colegas na organização das atividades, e aproveitei para observar como os alunos reagiam ao que era proposto, aos questionamentos, às informações que passávamos para eles. Essa parte de observação foi muito interessante para notar quais as coisas chamavam mais a atenção dos alunos, quais faziam eles se dispersarem, o que estava sendo interessante para eles e o que não estava, e como algumas reações podiam ser bem diferentes (ainda que nesse momento a turma da manhã e da tarde estavam juntas). Eu acho importante para quem está começando como professor ter uma idéia do que esperar dos alunos, e para isso, essa parte de observação é bem válida (BIANCA).
\end{abstract}

\title{
Concluindo
}

Há muitas questões em jogo e muito pouco espaço num artigo para discutilas. Gostaríamos de enfatizar que as impressões apontadas num semestre, pelos licenciandos que participaram da atividade, refletem nossas impressões coletadas ao longo de seis anos nessa mesma perspectiva. Além dessas apresentadas neste artigo, muitas outras poderiam ser enfatizadas, como a importância do planejamento, a vivência em sala de aula, a improvisação do trabalho pedagógico, a vontade de ser como uma "formiguinha" e mudar o mundo, as concepções alternativas, o desânimo em atuar na educação no Brasil, as boas experiências que fazem repensar a profissão professor, a avaliação do outro colega, a percepção sobre o ensino de epistemologia e o trato com a ciência, a importância dos momentos de interação e descontração na pousada, a percepção do respeito às diferenças, de um maior contato com os colegas, entre tantas outras. Mas ficamos por aqui e consideramos que todas as falas nas narrativas dizem muito sobre a possibilidade de aprender com o outro - aprender com a professora, com os colegas e também com os alunos como relata Clara: 
Acredito também que aprendemos muito com os alunos, e que eles puderam perceber que muitas coisas que eles nos falavam nós não sabíamos e que estamos interessados no que eles tinham para falar, e inclusive utilizávamos a informação passada por eles nas atividades e discussões seguintes. Acho que com isso o aluno se sente valorizado e participativo (CLARA).

No âmbito da proposta de inserção vivencial para a formação de professores de ciências apresentada neste artigo, entendemos ser pertinente e potencialmente transformador pensar aquela formação também a partir de articulações entre AD e CTS, realçando a pertinência do tratamento discursivo de termos/ conceitos tidos como não pertencentes ao corpo de conhecimentos científicos escolares tradicionais, mas que emergem com frequência crescente no ensino de ciências pensado em contexto sem a necessária reflexão.

Do mesmo modo, entendemos ser necessário incluir naquela formação e nas pesquisas de campo, aprofundamentos analíticos com respeito às dificuldades teóricas e metodológicas de propostas que buscam romper com percepções naturalizadas de ciência, de tecnologia, de sociedade, e de suas relações.

\section{REFERÊNCIAS}

APLLE, M. Ideologia e Currículo. 3. ed. Porto Alegre: Artmed, 2006.

CASSIANI-SOUZA, S. Leitura e Fotossíntese: Proposta de Ensino Numa Abordagem Cultural. Tese (Doutorado) - Unicamp, Campinas-SP, 2000.

CASSIANI-SOUZA, S.; PAULA, G. S.; ZIMMERMAN, N.; SCHMAL, A.; GIRALDI, P. Estudos sobre as possibilidades e limites dos estágios curriculares na formação de professores de biologia. Atas do Endipe, Recife, 2004.

DAGNINO, R. Neutralidade da ciência e determinismo tecnológico: um debate sobre a tecnociência. Campinas-SP: Editora da UNICAMP, 2008.

FLÔR, C. C.; CASSIANI-SOUZA, S. A história da ciência presente nos parâmetros curriculares nacionais. In: V Encontro Nacional de Pesquisa em Educação em Ciências, 2005, Bauru. Caderno de Resumos do VI Enpec. Bauru: Unesp, 2005. v. 1. p. 1-12.

HELLER, A. O quotidiano e a história. Rio de Janeiro: Paz e Terra, 1972. 
LINSINGEN, I.; CASSIANI-SOUZA, S.; PEREIRA, P. B. Repensando a formação de professores de ciências numa perspectiva CTS: algumas intervenções. Anais do Primer Congreso Argentino de Estudios Sociales de la Ciencia y la Tecnología, Buenos Aires, 2007.

LINSINGEN, I. Perspectiva educacional CTS: aspectos de um campo em consolidação na América Latina. Ciência \& Ensino (UNICAMP), v. 1, p. 01-16, 2007. Disponível em: $<$ http://www.ige.unicamp.br/ojs/index.php/cienciaeensino/article/view/150/108>.

MARQUES, L. R. Democracia radical e democracia participativa: contribuições teóricas à análise da democracia na educação. Educ. Soc., Campinas-SP, v. 29, n. 102, p. 55-78, jan./abr. 2008. Disponível em: <http://www.cedes.unicamp.br>.

NASCIMENTO, T. G.; LINSINGEN, I. Articulações entre o enfoque CTS e a pedagogia de Paulo Freire como base para o ensino de ciências. Convergência: Revista de Ciencias Sociales, año 13, n. 42, set./dez. 2006. México: UAEM. Disponível em: <http://www. uaemex.mx/webvirtual/wwwconver/htdocs/home.html>.

ORLANDI, E. P. Interpretação, autoria e efeitos do trabalho simbólico. Petrópolis: Vozes, 1996.

PATTO, M. H. S. O conceito de cotidianidade em Agnes Heller e a pesquisa em educação. Perspectivas, São Paulo, 16, p. 119-141, 1993. Disponível em: <http:// www.fclar.unesp.br/seer/index.php?journal=perspectivas\&page $=$ article \&op $=$ viewFil e\&path[] $=775 \&$ path []$=636>$.

PÊCHEUX, M. Por uma análise automática do discurso. Campinas-SP: Ed. Unicamp, 1990.

PIMENTA, S. O Estágio na Formação de Professores. [S.I.]: Cortez, 2000. 